\title{
Structure Analysis and Improvement of Diesel Engine Block
}

\author{
Weineng Zhang ${ }^{1, a}$, Xiaohui Cao ${ }^{1, b}$
}

${ }^{1}$ School of Automobile and Traffic Engineering, Jiangsu University, Zhenjiang 212013, China

${ }^{a}$ zwneng01@163.com, ${ }^{b}$ caoxh@ujs.edu.cn

Keywords: Diesel engine, Finite element, Stress, Deformation

\begin{abstract}
The finite element analytical model of a diesel engine is established to analyze the stress, the flatness, the roundness and the rate of light leakage of the diesel engine block .The analysis result shows that the optimized scheme improves the body's stress concentration and deformation obviously: the tensile stress between the upper cylinder sleeve shoulders spigot and the counter bore of cylinder head bolt decreases by $15 \%$ compares to the original diesel engine block. The maximum stress decreases obviously and the stress concentration region moves down slightly by changing the " $T$ " type stiffener above the head of the block into rectangular stiffener; the flatness of the end surface of cylinder liner spigot decreases by $11.3 \%$; the circularity and the rate of light leakage of each cross section on cylinder liner decreases obviously.
\end{abstract}

\section{Introduction}

The single-cylinder diesel engine has the properties of small volume, high power, high torque at low speed, good start-up and acceleration performance, low oil wear and cheap, and it has been widely used. Adopting the aluminum engine block can effectively reduce the total weight of the engine. But the elastic modulus of aluminum alloy is far less than that of cast iron, the deformation amount of the engine block and related parts sharply increase with the fuel gas maximum combustion pressure. Deformation of the cylinder liner will cause gas leakage, oily smoke, power down, fuel consumption increase, increase the possibility of piston scraping; Deformation of cylinder top surface will increase the possibility of the cylinder gasket and decrease mechanical efficiency, moving parts can't work normally. Otherwise, because of the high thermal conductivity of aluminum alloy, the heat of combustion chamber can transfer to crankcase easily and make the oil temperature rise so that lubrication performance of engine get worse, engine power decrease and can't work normally in serious case.

In this paper, a cast-iron single-cylinder diesel engine is researched. Structural strength and rigidity of the original diesel engine block, the cast- aluminum block and the improved castaluminum block are analyzed. The data of deformation of important parts of the body are obtained by the finite element method [1], and the contrastive analysis is made with body's stress and the flatness of the cylinder liner spigot end surface and the rate of light leakage of each cross section on cylinder liner.

\section{Finite Element Model}

The diesel engine block assembly parts are shown as Fig.1. 


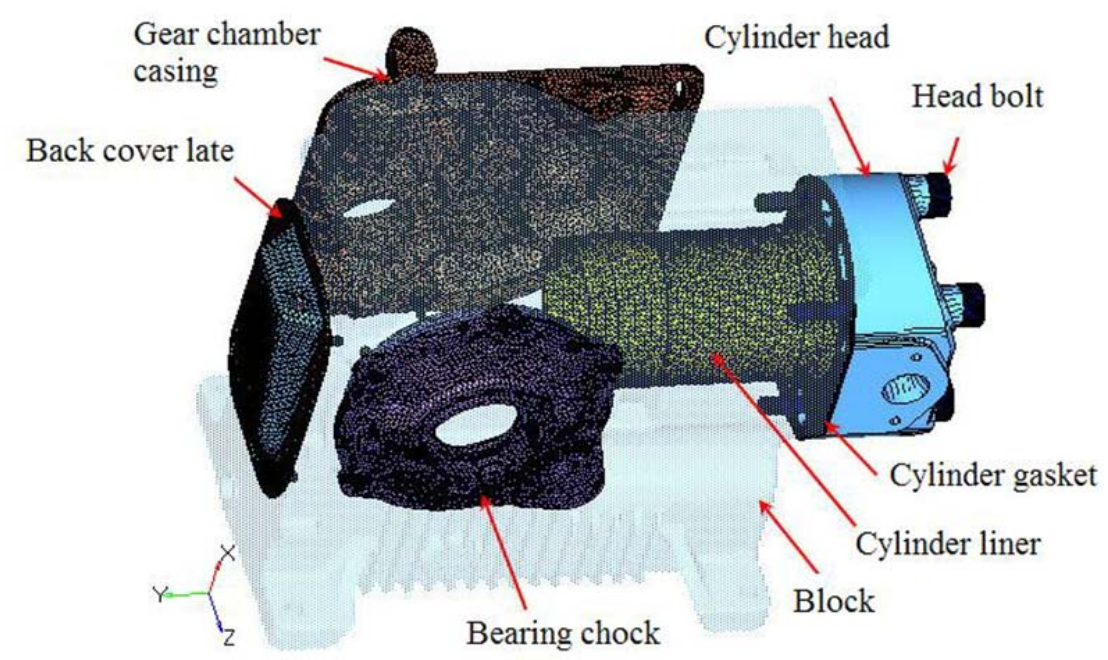

Fig. 1 Finite element model of original body of the diesel engine

\section{Boundary Condition and Calculation Schemes}

Boundary Condition. Displacement constraints of the X, Y, Z three directions are imposed on the location of the four bolt holes of the lower body. In order to investigate the effect of side pressure of piston, forced with the maximum side pressure of piston [2].

Calculation Schemes. Schemes1: The indexes of the stress, the flatness of the cylinder liner spigot end surface and the rate of light leakage of each cross section of the diesel engine block combined parts can be got by analyzing the cast-iron engine block according to finite element method. Those indexes are as evaluating indicator of the improved schemes.

Scheme2: Changing the cast-iron engine body into cast aluminum engine body, and then analyzing the evaluations indexes of scheme 1 and scheme 2 by finite element method contrastively.

Scheme3: Increasing the depth of the counter bore of cylinder head bolt from $5 \mathrm{~mm}$ to $12 \mathrm{~mm}$ and thickness of the four stiffeners behind the cylinder head bolt from $6 \mathrm{~mm}$ to $10 \mathrm{~mm}$, dredging the partial metal near the two bolts on the upper body, increasing the area of the stiffener over the body's head, changing the " $T$ " type stiffener into rectangular stiffener above the head of the body, dredging the partial metal below the push beam hole. Then analyze the evaluating indicator of scheme 3 and scheme 1 by finite element method contrastive.

Scheme4: Increasing the depth of the counter bore of cylinder head bolt from $5 \mathrm{~mm}$ to $15.2 \mathrm{~mm}$ [3], other improvement measures are same as scheme3. Then analyze the evaluating indicator of scheme 3 and scheme 1 by finite element method contrastively.

\section{Stress Analysis nearby the Cylinder Head Bolt of the Body}

It finds that the trends of the body's stress distribution of the four schemes and the relative position of the stress concentration are same essentially by finite element method. 


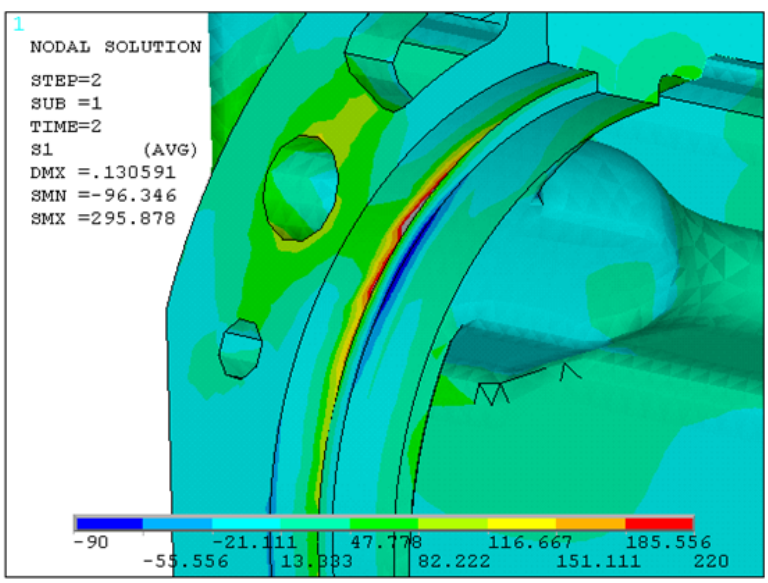

Fig. 2 The stress above the upper cylinder sleeve shoulders spigot in scheme4

The positions of threaded connection are simulated by using common coupling surface because of tooth of the thread bolt can't be simulated accurately, so the stress of the region is too large. The maximum stress of the engine body appears above the upper cylinder sleeve shoulders spigot except the positions of threaded connection: Above the upper cylinder sleeve shoulders spigot, the cylinder head bolt stretch the bolt hole [4], and cylinder head causes a downward pressure on the cylinder liner spigot end surface by compacting cylinder gasket and cylinder liner boss, so a large tensile stress is pressurized on this position.

The tensile stress of this position reaches $250 \mathrm{MPa}$ in scheme 1 , but is $220 \mathrm{MPa}$ in scheme 4 that decreases by $15 \%$ than the original engine body, as is shown in the Fig. 2.

\section{Deformation of the Cylinder Liner Analysis}

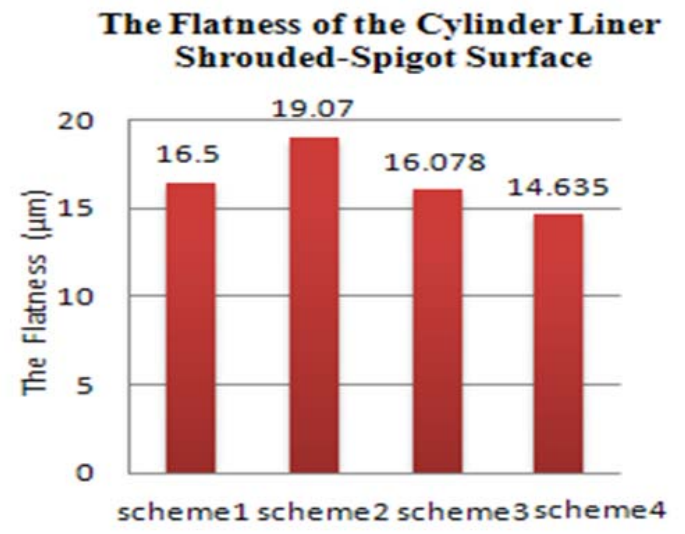

Fig. 3 The flatness of cylinder liner shrouded-spigot surface

Fig. 3 shows that the flatness of cylinder liner spigot end surface of four schemes are $16.5 \mu \mathrm{m}$, $19.07 \mu \mathrm{m}, 16.078 \mu \mathrm{m}$ and $14.635 \mu \mathrm{m}$. Because the depth of the counter bore of cylinder head bolt that increases from $5 \mathrm{~mm}$ to $15.2 \mathrm{~mm}$ is longer than that of the upper cylinder sleeve shoulders spigot in scheme4, which causes the increment of the distance between the first bolt thread and the cylinder liner spigot end surface, this weaken the impact of fuel gas maximum combustion pressure inside of cylinder, the flatness of the cylinder liner spigot end surface decrease obviously.

\section{The Circularity and the Rate of Light Leakage of each Cross Section on Cylinder Liner}

Forty-six cross sections are selected to analyze on the cylinder liner bore surface in order to evaluate the deformation of the cylinder liner better, they are numbered from 1 to 46 [5]. 


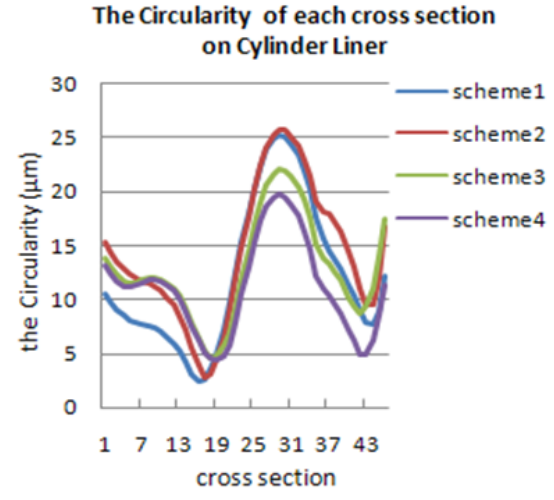

Fig. 4 The circularity comparison

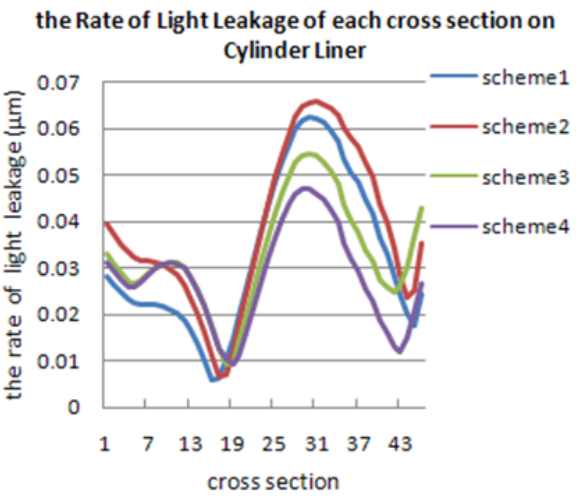

Fig. 5 The rate of light leakage comparison

As shown in Fig.4 and Fig.5, the circularity and the rate of light leakage of each cross section on cylinder liner in scheme 2 increase in different extent compare with schem1, especially cross sections of number 30 to 46 . But the circularity and the rate of light leakage in scheme 3 and scheme4 decrease in different extent. Improvements in scheme4 reduce the deformation of the cylinder liner, so the circularity and the rate of light leakage of each cross section on cylinder liner decrease obviously.

\section{Conclusions}

This paper adopts flowing improvements: Increasing the depth of the counter bore of cylinder head bolt from $5 \mathrm{~mm}$ to $15.2 \mathrm{~mm}$, and the thickness of the four stiffeners behind the cylinder head bolt from $6 \mathrm{~mm}$ to $10 \mathrm{~mm}$, dredging the partial metal near the two bolts on the upper body, changing the "T" type stiffener into rectangular stiffener above the head of the body, increasing the area of the stiffener over the body's head, dredging the partial metal below the push beam hole. And the following conclusions are obtained:

(1)The maximum tensile stress above the upper cylinder sleeve shoulders spigot decreases obviously, the range of tensile stress enlarges and moves down.

(2)The flatness of the cylinder liner spigot end surface decrease obviously.

(3)The circularity and the rate of light leakage of each cross section on cylinder liner decrease obviously.

\section{Acknowledgements}

This work was financially supported by A Project Funded by the Priority Academic Program Development of Jiangsu Higher Education Institutions (PAPD).

\section{References}

[1] G.H. Xue, X.S. Yu, P.S. Liu: Journal of Aerospace Power, Vol.27 (2012) No.5, p.1146

[2] M.L. Cao, A.Z. Bu, D.T. Li, S.L. Jiang, H. Wang: Transactions of CSICE, Vol.20 (2002) No.5, p.447 (In Chinese)

[3] F. Dong, S.L. Jiang, C.H. Guo and Y.L. Ding: SMALL INTERNAL COMBUSTION ENGINE AND MOTORCYCLE, Vol. 37 (2008) No.3, p.42 (In Chinese)

[4] L.S. Yang: Internal Combustion Engine Design, (China Agricultural Machinery Press, China 1984), p358 (In Chinese)

[5] Q.Z. Ma, S.L. Jiang, C.H. Guo. X.L. Yao, Q. Gu, B. Dong, Q.Ye: Chniese Internal Combustion Engine Engineering, Vol. 29 (2008) No.4, p.59 (In Chinese) 